\title{
DESAUSSURE ANTE LOS LINGÜISTAS DEL SIGLO XIX Y EL PROBLEMA DEL SUJETO
}

\author{
JUAN MANUEL FUSTES \\ (UNIVERSIDADDELAREPÚBLICA, URUGUAY)
}

\begin{abstract}
RESUMEN: Este artículo tiene como propósito generar un diálogo entre las ideas de Ferdinand de Saussure, tal como son expresadas en su Cours de Linguistique Générale, y otros influyentes lingüistas contemporáneos a él.

Nos concentramos particularmente en las concepciones que se pueden deducir de las aserciones acerca de lengua/lenguaje, hablante y signo lingüístico, based tomando en cuenta los aspectos sociales y biológicos y un tercer aspecto que podríamos considerar como el específicamente lingüístico.

Subrayamos, asimismo, la vigencia de esta discusión para la lingüística actual.
\end{abstract}

\begin{abstract}
The aim of this article is to establish a dialogue between Ferdinand de Saussure's ideas in Cours de Linguistique Générale and those of other influential linguists of his time. The main focus is placed on the conceptions that can be derived from Paul's, Whitney's and Brugmann's assertions about language, speaker and linguistic sign. Those statements generally take into account social and biological aspects but they also let make out a third aspect which is neither social nor biological and which may be considered to be the specifically linguistic.

The relevance of this discussion for current Linguistics is also underlined.
\end{abstract}

\section{PROPÓSITOS}

Nos planteamos aquí 1 la posibilidad de rastrear el espacio del sujeto en la lingüística precedente a de Saussure, a través de la relación lingüista / lengua / hablante. En medio de esta búsqueda, intentaremos darle un justo lugar al ginebrino como mojón importante para la puesta en relevancia de esta cuestión, alejándolo a la vez del carácter meramente fundacional que se le suele atribuir.

Aceptamos la idea de que de Saussure se ubica en una lingüística ya "moderna" (siguiendo el sentido que nos indica Milner, 1989) desde algunas décadas, liberada de sus compromisos con la gramática en su acepción prescriptiva y en su concepción premoderna (precientífica o aun medieval) y e incluso con la visión romántica relativa a la idea de decadencia de las lenguas.

${ }^{1}$ El presente trabajo surge en el seno del grupo Lengua/Lenguaje y Acontecimiento didáctico, que se inscribe en la línea de investigación Estudio de lo Didáctico como Acontecimiento Discursivo e Intersubjetividad (EDADI), desarrollada desde el año 2002 en el Departamento de Psicología de la Educación y Didáctica del Área de Ciencias de la Educación de la Facultad de Humanidades y Ciencias de la Educación de la Universidad de la República. Se relaciona, además, con trabajos de investigación llevados adelante en el Departamento de Psico y Sociolingüística del Instituto de Lingüística de la misma Facultad. 
Esa "liberación" de algunas tendencias y esa modernidad a la que aludimos ponen a de Saussure inserto en las tendencias científicas de fines del siglo XIX, que en su discurso se reflejan en un sociologismo y un psicologismo oscilantes, es decir, a fin de cuentas, en una lingüística que lograría liberarse de campos complementarios. Por otro lado, seguramente sin que él lo pudiera notar, se constituye en autor de hallazgos que sólo algunos de sus sucesores se encargarán de explotar: las cuestiones del signo, el significante, y un hablante que soporte esas tres tendencias: sociologismo, psicologismo y arbitrariedad del signo, con la posibilidad de liberarse de los campos complementarios y vislumbrar una lingüística que halla el dominio propio de la lengua.

Este es, a nuestro entender, el meollo de la posible revolución saussuriana, en la medida en que dependió de sus sucesores el hecho de ir un paso más allá en esa tensión creada, o quedarse en cualquier estado pacífico anterior.

Sin pretender obtener de de Saussure una respuesta final, aspiramos, por una parte, a reconciliarlo para la historia de la lingüística con los lingüistas que lo precedieron, marcar algo de su potencial innovación, en particular a través de un pasaje del Curso de Lingüística General, y por otro lado, separarlo de la frialdad marmórea a la que el museo de la lingüística lo llegó, quizás, a confinar.

\section{ANTECEDENTES: LOS LINGÜISTAS DELSIGLO XIX Y SUS BÚSQUEDAS}

Si tomamos como momentos germinales de la lingüística propia del siglo XIX a las observaciones del inglés Sir William Jones (1746-1794) acerca del sánscrito² ${ }^{2}$, nos encontramos con un hombre de ciencia, en el sentido universalista del siglo XVIII, que probablemente aún no se coloca en la posición de quien deberá lidiar con las lenguas, pero sí ofrecerá observaciones que proveerán de elementos susceptibles de análisis adecuados a las exigencias de matematización de una nueva ciencia.

Pero, además del requisito de ciencia moderna, Sir William Jones colocó en el hallazgo del sánscrito su fe de hallar huellas trascendentes de lo humano y lo pasado, lo original, de las que el significante de esta lengua oriental sería portador ${ }^{3}$. Esta faceta del hallazgo apela, a nuestro entender, al sujeto (sea o no lingüista) en relación con un objeto fantasmático: las lenguas conocidas como testimonios de una posible plenitud: la lengua originaria.

Es así que este ejercicio de reconstrucción es una tentación muy fuerte, que se constituirá, en pocas décadas, en una disciplina: la que Schlegel denominará "gramática comparativa". La formulación de estas relaciones, reglas, da lugar a un cierto desplazamiento del objeto: la lengua pasa de ser un medio para llegar al conocimiento de lo primigenio a ser un objeto de estudio en sí.

\footnotetext{
${ }^{2}$ Cabe anotar que las diferentes historias de la lingüística nos muestran antecedentes a su trabajo (Véanse, por ejemplo, Robins, 1984: 185-190; Mounin, 1967).

${ }^{3}$ El ejemplo más extremo de la búsqueda de lo original se encuentra en Schleicher, que en 1861, en su "Compendio de la gramática comparada de las lenguas indoeuropeas" (o indogermánicas, como calco de indogermanisch, término usado en lengua alemana), presenta a la lengua indoeuropea (por primera vez claramente, según Mastrelli, 1953: 12) como una lengua que realmente existió y llegó a escribir en ella la famosa fábula de la oveja y los caballos.
} 
Esto significa, sin embargo, el interjuego de varias tendencias entre cientificismo y romanticismo: por un lado, la exaltación de los hallazgos y productos de las reconstrucciones, con la consiguiente atribución de valores a los estadios lingüísticos hallados, para hablar en términos de decadencia de las lenguas. Por otro lado, la faceta darwinista de las lenguas como organismos vivos que nacían, maduraban, envejecían y morían, con un correlato en evolución o decadencia ${ }^{4}$.

Sin embargo, esta búsqueda romántica (usando un adjetivo que valdría la pena redefinir en nuestro enfoque) no está en colisión con el "espíritu científico", aunque por momentos olvida su compromiso con la física, lo que hace que el rigor fonético quede en segundo plano. Ese olvido o postergación, esa separación del llamado de lo real representa, a nuestro entender, una muestra de que la búsqueda subjetiva de esos lingüistas surgía de la angustia inherente a su condición de hablantes (Milner, 1980, acerca del lingüista deseante), subjetivamente ubicados en una relación singular con su propia lengua, y a su vez con las otras lenguas de las que no eran hablantes, en posición similar a aquel que desea ser hablante de una lengua extranjera ${ }^{5}$. Por lo tanto, la posición de estos estudiosos se asemeja a lo que decíamos sobre quien desea aprender una lengua extranjera, en el sentido de que, desdeñando el presente y las lenguas actualmente habladas (por lo tanto también su propia lengua materna) y hallando en ellas insuficiencias expresivas $^{6}$, los lingüistas vislumbraban la posibilidad de lenguas ideales, ubicadas en un tiempo originario (en un relato de la historia de la humanidad quizás similar al relato de la propia vida individual) de modo que veían la posibilidad de lenguas más armónicas, que articulaban las ideas y quizá incluso las relaciones lógicas en mejor manera, todo de acuerdo a sus propios ideales estéticos e intelectuales.

Más síntomas de la preeminencia del deseo de ese reencuentro con los orígenes están dados en la llamada paleontología lingüística, a través de la cual se llegó a deducir cuáles habrían sido las características del pueblo indoeuropeo (por ejemplo si al reconstruir *ekuos afirman que los indoeuropeos poseían caballos domésticos). Subrayamos aquí lo extremo de esa etapa, puesto que no solamente se está aceptando la existencia de esos significantes, sino que además se los está haciendo signos, atribuyéndoles significados, la única forma de encontrar a los hablantes detrás de eso.

Esta idealización que comprende a las lenguas y a los hablantes, se verá superada recién hacia fines del siglo XIX, cuando la maravilla del sánscrito se apague y su efecto cese y sean ánimos menos románticos y más positivistas los que se encarguen de estos temas. Dicho de otra manera, la superación de esta fase, está dada por la fuerza de los

${ }^{4} \mathrm{Si}$ se quiere, en vez de una evolución hacia el perfeccionamiento más típica del darwinismo, el camino se daba en la dirección contraria. De hecho, algunas lenguas, como el sánscrito, el latín y el griego, eran consideradas, por su complejidad sobre todo morfológica, representantes de una racionalidad más desarrollada (Mc Mahon, 1994: 18) y sobre todo testimonios de una Ursprache (lengua original) de la que nos quedarían sólo pálidos reflejos.

${ }^{5}$ Desarrollamos esta cuestión del sabe de lengua extranjera en un trabajo reciente, basándonos en las apreciaciones de Anderson (2001) acerca del aprendiz de lengua extranjera y en las de Melman (1992) acerca del inmigrante. Allí planteábamos que ante el hablante la propia lengua se presenta por momentos insuficiente, y a partir de esa insuficiencia la lengua de otro u otra lengua se visualiza como una posible completud, donde todo puede ser dicho.

${ }^{6}$ Que son en realidad inherentes al lenguaje, puesto que, como establecíamos en ese trabajo, la alteridad de la lengua respecto al nivel particular de la subjetividad coloca al sujeto en posición de angustia. 
lingüistas que desean ser científicos, así es que de Saussure, ya colocándose desde fuera de esta concepción, remarcará:

"À lire Bopp et ses disciples, on croirait que les Grecs avaient un bagage de racines et de
suffixes, et qu'ils s'occupaient à confectionner leurs mots en parlant, que pater, par exemple,
était pour eux rac. pa+suff. ter, que doso dans leur bouche représentait la somme de do + so
+ une désinence personnelle, etc. " (de Saussure, $1965: 252$ )

No podemos, sin embargo, afirmar, que hubo un período delirante de la lingüística en que todo se encaminó a una búsqueda ciega, siempre estuvo presente la tensión entre el lingüista con su deseo y el lingüista como científico, y los lingüistas del siglo XIX discutieron sobre el rigor y dieron a entender sus ideas de la relación entre cuerpo, lengua y hablante, al principio planteando al lenguaje como un hecho natural (y del cuerpo), de modo que su conformación depende de los órganos que lo producen (Tagliavini, 1963: 103).

Sabemos que las ópticas más radicalmente fisiologistas dieron paso a las psicologistas, con la llegada de los neogramáticos ${ }^{7}$ y su derrumbamiento del mito de la decadencia de las lenguas, a través de una visión instantaneísta y relativista:

1) que indicaba que los principios que rigen los cambios en la actualidad no tienen razón para ser diferentes a los que los regían en tiempo antiguo;

2) que proponía que las "pérdidas" de elementos que sufren las lenguas, leídas como simplificaciones, no implican el hecho de que las lenguas modernas hayan perdido la capacidad de expresar categorías gramaticales, las cuales, así como antes estaban expresadas por medios morfológicos, hoy pueden materializarse a través de estrategias alternativas, como el uso de verbos auxiliares.

Estos mecanismos operan, según los neogramáticos, en forma imperceptible para los hablantes que no pueden hacer nada para detenerlos o incluso preservar los elementos gramaticales comprometidos. He aquí un detalle no menor, puesto que, con esta observación, los neogramáticos nos están diciendo que hay algo como una fuerza exterior al hablante y que hay una relación de imposibilidad (de control) del hablante respecto a la lengua.

${ }^{7} \mathrm{El}$ advenimiento de esta corriente se presenta en varias historias de la lingüística como un hecho de corte radical respecto a la lingüística anterior y que encuentra en la geografía lingüística schuchardtiana un contendor acérrimo. Sin embargo, nosotros nos animamos a subrayar con Tagliavini (1963: 189) que, por un lado, muchas ideas de los neogramáticos ya habían, al menos, penetrado en la praxis de los viejos gramáticos y por otro lado, respecto al aparente distanciamiento de la empiria que les reprocharían la geografía lingüística y la dialectología, los neogramáticos se centran en el estudio del idiolecto y del promedio lingüístico, que será objeto central del próximo apartado. 


\section{DE SAUSSURE EN DIÁLOGO CON SUS CONTEMPORÁNEOS: PAUL, WHITNEY, BRUGMANN.LA CUESTIÓNDE LOPROPIO DE LA LENGUA EN UNA LINGÜÍSTICA "QUEDESEA SER UNA CIENCIA"}

Este apartado surge principalmente de las indagaciones que hiciéramos en ocasión de una revisión de las concepciones predominantes en la lingüística del siglo XIX, sobre todo en lo que hace a la cuestión del cambio lingüístico (Fustes, 2008). En ocasión de Ferdinand de Saussure (y principalmente de su Curso de Lingüística General en la versión difundida por Bally y Sechehaye desde 1916), hemos hallado un espacio entre sus indagaciones y las de algunos de sus contemporáneos (en especial W. D. Whitney y H. Paul) para indicar algunos lugares de confrontación teórica poco aludidos por la lingüística actual, pero que, a nuestro entender, continúan vigentes.

Creemos que la relación entre los estudios contemporáneos a de Saussure y las ideas presentadas en el curso pueden ser aún mejor articuladas, incluso si somos conscientes del carácter fragmentario que tiene el Curso de Lingüística General en tanto libro, con el ordenamiento particular que dieron sus discípulos, y las ideas oscilantes que se dejan ver incluso dentro de un solo capítulo. Más allá de esta dificultad, o aun intentando adoptarla a nuestro favor, y a modo de ejemplo de una posible indagación, hemos decido tomar (no azarosamente) un pasaje del Curso de Lingüística General, en particular el apartado 2 del capítulo III de la Introducción (Place de la langue dans les faits de langage, de Saussure, 1965: 27-35) en el que de Saussure intenta separar lo específico de la Lingüística (place de la langue) y descartar los otros hechos del lenguaje que no le serían propios ${ }^{9}$.

En esa tarea, llega a dividir, como sabemos, lo psíquico, lo fisiológico, lo físico y finalmente lo estrictamente lingüístico. Cada uno de esos dominios puede en mayor o menor medida prescindir de lo subjetivo o, digamos mejor, sin utilizar un término marcado, de lo que pertenece a la esfera del individuo o del hablante (entendido desde cualquier punto de vista). Sin embargo, en esa sección no le será posible prescindir del hablante, en tanto cuerpo: "est actif tout ce qui va (...) à l'oreille de l'autre sujet”, "la partie psychique localisée dans le cerveau" (de Saussure, 1965: 29, subrayado nuestro); o en función de características psicológicas: "une faculté d'association et de coordination" (de Saussure, 1965: 29), pero remarcando que lo que hace estrictamente a la lengua no está en ninguno de esos niveles sino en el del hecho social ("fait social”). Buscamos respondernos cómo se expresa lo no individual, lo no singular, que quedaría comprendido por la lengua como hecho social.

Sabemos que estas concepciones psicologistas y sociologistas deben mucho a las ciencias sociales y a la psicología de su época y, para que esta observación un poco determinista no cancele la discusión, proponemos operar con la pregunta sobre cómo se resuelve la articulación entre lo individual y lo social.

\footnotetext{
${ }^{8}$ Evocando la frase de apertura del prefacio de "Introducción a una ciencia del lenguaje" de J.-C. Milner (1989: 11).

${ }^{9}$ Concentrarnos en este pasaje implica, prescindir, al menos parcialmente, de teorías como las del signo y del valor, que podrían sernos de auxilio para explicar muchas de las preguntas que nos hacemos atendiendo sólo a este apartado.
} 
Las ideas de de Saussure en ese punto son embrionarias aún y nos colocan ante una bifurcación: por un lado, la idea de los neogramáticos (cuyo mejor ejemplo podría ser Hermann Paul) de que la lingüística puede operar por un promedio lingüístico de todos los hablantes y por otro, la prefiguración de un orden propio de la lengua que no coincide con la suma total de los individuos y que a la vez no prescinde de la inclusión de lo singular.

Para este primer sentido, entonces, de Saussure (1965: 29) nos dice: “il s'établira une sorte de moyenne" en el mismo sentido en el que Paul propone que para estudiar un estado de lengua dado es necesario estudiar los idiolectos, o sea, la lengua particular de cada hablante (Koerner, 1973: 183). En este sentido, se reconoce sólo la existencia de la suma de hablantes para aprehender la lengua (a este respecto podría estudiarse cómo la dialectología, la geografía lingüística y la sociolingüística variacionista son continuadoras de esta idea). Con este punto de vista no se nos puede responder a la pregunta, que allí naturalmente surge, sobre qué hace que esas individualidades, sin algo que las trascienda, puedan tener algo en común que a la vez no es un rasgo genético o innato. Se nos ocurre, quizás adelantando parte de nuestras conclusiones, que eso que las trasciende, a falta de otra cosa que no sea hablantes singulares, tiene que estar en la condición subjetiva de cada uno de ellos.

La otra lectura, la que sugiere de Saussure con su término "cristallisation sociale" (entre otras expresiones que indicaremos) nos presenta una potencialidad nueva: la de considerar un tercer orden, de conciliación entre lo no puramente individual, el dominio de la lengua como algo exterior a su voluntad y el dominio de la parole en el que el sujeto es amo de sus enunciados, como veremos más adelante dicho por el mismo de Saussure.

Entendemos que se vislumbra esa conciliación en la medida en que algunos pasajes de lo escrito por los lingüistas aquí confrontados aluden a términos que comprenderían lo singular y lo general a la vez, y que podrían constituir el ámbito de esa lengua que sólo por efecto del ser hablante será tal, es decir, algo que se halla en otros registros además del mero real de la cadena material.

En William Dwight Whitney ${ }^{10}$ en su Language and the Study of Language (en adelante LSL) de 1867, la relación hablante individual - comunidad aparece en este pasaje de la siguiente manera:

"aunque los individuos son los únicos agentes definitivos en la formación y modificación de cada palabra y significado de una palabra, sin embargo es la comunidad la que hace y cambia su lenguaje" (Whitney en LSL apud Koerner, 1973: 155)

"La comunidad" aparece como agente en esa frase de Whitney, con lo que vemos la sugerencia de un orden de cosas propio de la lengua. Si bien coloca a la lengua (language) del lado de la comunidad, a su vez la define como "un sistema de sonidos con contenido inteligible" (Whitney en LSL apud Koerner, 1973: 160): en términos de lo real que hay en ella (sonidos) y de lo subjetivo de la comprensión o interpretación (inteligible), con existencia en la realidad sólo "en las mentes y en las bocas de aquellos que [la] usan" (Whitney en LSL apud Koerner, 1973: 160). De retorno y contemporáneamente, Whitney, en su trabajo Language and Growth of Language (de 1875, en adelante LGL), atribuye a lo lingüístico un

${ }^{10}$ Autor que, según concluye Koerner (1973: 147), De Saussure habría leído muy pronto en su carrera académica y con cuya labor, según atestiguan los mismos manuscritos de De Saussure, habría estado muy familiarizado (1973: 149). 
espacio propio, pues dice: “...las facultades son una cosa, y sus productos elaborados otra muy diferente" (Whitney en LGL apud Koerner, 1973: 161).

Hacia 1894, y en franca conciliación con la producción de Whitney en Estados Unidos (que databa de 1867, 1875 y sucesivas traducciones al holandés, alemán, francés, italiano y ruso) se elabora un volumen conmemorativo de este lingüista estadounidense en el ámbito del malfamado y maltratado ${ }^{11}$ grupo de los neogramáticos. Es allí donde Brugmann, en el número 19 del Journal of American Oriental Society (apud Koerner, 1973: 175), revivifica las ideas de Whitney, retomando e integrando muchas de sus ideas del campo de la lingüística general, haciendo alusión a términos como Sprachgefühl Aller (instinto lingüístico de todos) como lugar de la aceptación y triunfo de las innovaciones lingüísticas y, por lo tanto -deducimos (o inducimos) nosotros- lugar de la lengua.

Será también Hermann Paul, siempre desde la escuela de los Junggrammatiker, desde 1886, un asimilador de estas cuestiones en sus Prinzipien der Sprachgeschichte (Principios de historia de la lengua). Las reflexiones de Paul trascienden, de hecho, ampliamente el mero principio de necesidad de la ley fonética que pareció ser, según muchos lingüistas del siglo XX, uno de los pocos aspectos visibles de su escuela. En el libro que mencionamos, en su edición de 1909 ${ }^{12}$, Paul plantea una distinción que resultará fundamental en su teoría del cambio lingüístico: aquella entre sentido usual y sentido ocasional. A través de esta distinción, coloca en el nivel de las representaciones de la comunidad aquello que pertenece al sentido usual y en el nivel de las singularidades de la enunciación lo que pertenece al sentido ocasional:

\footnotetext{
"Nous comprenons donc par sens usuel le contenu de représentation général associé à un mot pour qui appartient à une communauté linguistique donnée, et par sens occasionnel le contenu de représentation que le locuteur associe au mot lorsqu'il l'emploie, sens dont il escompte que l'allocutaire l'associe lui aussi au mot" (Paul, 1909: 6).
}

La significación ocurre en el acto individual y singular del sentido ocasional, y el lazo entre significante y significado (dicho en términos saussurianos), que podemos llamar significación, ocurre para Paul en lo que llamaríamos en términos actuales como interacción o intersubjetividad, merced a la intervención de un tercer elemento: " $Q u$ 'un lien au concret soit établi par le mot en soi ou non, d'autres facteurs doivent entrer en jeu pour préciser ce lien" (Paul, 1909: 10).

Mientras tanto, el sentido usual se encontraría en el nivel de la lengua, en el que el lazo estaría dado por algún elemento que trasciende lo particular y que el hablante singular no estaría en condiciones de manejar.

Ese lugar de imposibilidad o incompletud que remarca de Saussure al decir que la lengua no está completa en ningún hablante sino en la masa: “car la langue n'est complète dans aucun, elle n'existe parfaitement que dans la masse" (de Saussure, 1965: 30), Paul lo encuentra encarnado claramente en el nuevo hablante (donde además se opera el cambio linguiístico), donde lo que es ocasional, del acto individual, se vuelve lengua.

${ }^{11}$ Decimos esto en función del tratamiento que le prestaron en general los lingüistas posteriores a De Saussure en el siglo XX.

${ }^{12}$ La cuarta y penúltima, llegada a nosotros en forma parcial a través de una traducción francesa. 
Si bien no hay en Paul tan claramente una concepción de lengua como la que presenta de Saussure en el sentido de sistema, puesto que suele tratar al signo en forma aislada e independiente de los demás, sí está presente una idea de lengua que entra en esta discusión en que oponemos a nuestros tres lingüistas ${ }^{13}$.

El acceso a la lengua del sujeto siempre es parcial respecto al saber de lengua del que la comunidad - sociedad - masa es depositario, puesto que incluso tomando la lengua de sus prójimos, el reflejo del saber de éstos sobre la enunciación ${ }^{14}$ es incompleto, infiel, de modo que lo que se presenta ante el sujeto es el significante: "L'apprentissage par la définition n'est possible qu'à un stade relativement avancé de maîtrise de la langue; et même à ce stade, un tel mode d'apprentissage est de l'ordre de l'exception. L'enfant n'entend que des emplois occasionnels du mot" (Paul, 1909: 16).

El hablante sería entonces amo de los signos que llegaron a él desde fuera, presentados en forma de significantes, si tomamos en cuenta lo que hemos esbozado anteriormente. Por eso la cuestión de la significación parecería quedar fuera de la lengua, si ésta es el lugar de lo exterior, pues nos dice de Saussure: "le côté executif reste hors de cause, car l'exécution n'est jamais faite par la masse; elle est toujours individuelle, et l'individu en est toujours le maître; nous l'appelerons la parole” (de Saussure, 1965: 30).

Podríamos decir que el ámbito de la lengua, según lo que vemos en estos pasajes, es aquel en el que el sujeto no es amo, es decir, el signo no está dentro de lo que es del orden de la lengua.

De esta manera vemos abrirse, ya en de Saussure pero también en sus contemporáneos aquí analizados, en medio de la difícil articulación entre lo individual y lo social, un tercer espacio para lo que es propio de la lengua. Esta articulación habría sido imposible si hubieran sólo continuado concibiendo a estos dos campos como meramente complementarios (véase al respecto Henry, 1992).

Si retomamos lo dicho anteriormente, en lo específico de la lengua como "cristalización social", este adjetivo se entiende meramente como lo no individual o como lo supraindividual y, dicho en otros términos, algo que para el sujeto está de un lado Otro. Así, si la lengua es social, es alteridad, pero alteridad de retorno en el hablante.

Decimos, entonces, que podemos sobrepasar, con el mismo de Saussure, las ideas de "une sorte de moyenne", "des empreintes qui arrivent à être sensiblement les mêmes chez. tous", "la somme des images verbales emmagasinées chez tous les individus", "un système grammatical existant virtuellement dans chaque cerveau" (de Saussure, 1965: 30) como descripciones fenoménicas para adoptar la segunda formulación, aún embrionaria en este pasaje, de focalizar sobre lo que es propio de la lengua.

Este es el camino de la dimensión subjetiva en el lugar del tercer espacio que trasciende la complementariedad, sobre todo si inmediatamente el mismo de Saussure nos dice: "car la langue n'est complète dans aucun, elle n'existe parfaitement que dans la masse" (de Saussure, 1965: 30).

${ }^{13}$ En trabajos muy recientes, Koerner (2008) estudia con profundidad los vínculos entre F. De Saussure y H. Paul. Por la contemporaneidad del trabajo de este autor con el nuestro, no hemos podido, lamentablemente, incluir en este trabajo sus últimos aportes.

${ }^{14}$ Somos conscientes del uso preteórico que estamos dando aquí a algunos términos como enunciación, significación, etc. 


\section{AMODODE CONCLUSIÓN}

Ante la falta de resolución de este nudo, no nos queda más que esperar hasta que Lacan con su formulación del Gran Otro, intente vencer esta dificultad, aunque no sin que nos queden aún problemas por tratar, sobre todo si del psicoanálisis volvemos a la lingüística. Esas ideas no forman parte, sin embargo, de lo aquí discutido, aunque pensamos que hemos intentado una convergencia con la prefiguración de un concepto que nos sugiere la alteridad presente en el sujeto singular en la medida en que éste se ve fundado por la lengua-lenguaje-masa.

Consideramos que el pasaje del Curso de Lingüística General al que hemos aludido en el apartado anterior nos inscribe cabalmente a de Saussure en su momento, respecto a sus antecesores, sus contemporáneos y, en cuanto a lo que particularmente nos interesa, respecto a las preocupaciones acerca del tratamiento que la lingüística pueda hacer de la subjetividad.

Creemos que el problema de la subjetividad se puede rastrear incluso contando con la problemática que resulta de la pluralidad de tendencias del pasaje del Curso de Lingüística General al que nos hemos referido, presentada en forma de oscilaciones, enmarcadas en el gran proyecto de normalización de la lingüística como ciencia moderna que intentaron cumplir diversos lingüistas desde Schlegel (o quizá antes), afectados por los modelos de las demás ciencias (como la economía, biología, sociología, psicología).

Entendemos que son sanas las preguntas que le quedan a la lingüística si hemos decidido que su especificidad está más allá del linguistic average, más allá de esa ilusión empirista de aprehender la lengua puesta en práctica aun sin haber decidido qué hacer con ese elemento "Aller" (de todos) que hay en ese Sprachgefühl (instinto lingüístico).

La reconciliación con esta pregunta se dificulta por la poca accesibilidad al corpus de la lingüística como cadena de textos, contando con la lectura de los lingüistas del siglo XIX, debido a falta de nuevas ediciones, de difusión de los textos, de traducciones y de inclusión de estas temáticas en la formación de los actuales lingüistas. Desearíamos que de Saussure no funcionara como mito fundador si ese mito ha de crear una muralla que separa a la lingüística fundada por él de aquella en la que él fue lingüista. Esta apertura ya ha tenido varias tentativas (Milner, 2002; Silveira, 2007) y esperamos que esta que llevamos adelante aquí pueda ser una más.

\section{REFERENCIASBIBLIOGRÁFICAS}

ANDERSON, P. (2001) "La langue étrangère et l'envie d'apprendre" en http://laseldi.univ-fcomte.fr/ utilisateur/panderso/fichiers_5.pdf (último acceso 25/11/2006).

DE SAUSSURE, F. de (1965) Cours de Linguistique Générale. Paris, Payot.

FUSTES, J. M. (2007) La lengua extranjera desde una didáctica centrada en el saber. Monografía Seminario "Interacción y didáctica" 2003, Portal EduMec (Ministerio de Educación y Cultura), http://www.edu.mec.gub.uy/articulos/fustesSABERlengextr.pdf

.(2008) El cambio lingüístico y la Lingüística del siglo XIX. La posibilidad de su aprehensión en la búsqueda de una consistencia para el lenguaje. Monografía de Lingüística Histórica, Facultad de Humanidades y Ciencias de la Educación, Montevideo, inédito. 
HENRY, P. (1992) A ferramenta imperfeita. Língua, Sujeito e Discurso. Campinas, Editora da Unicamp.

KOERNER, E. F. K. (1973) Ferdinand de Saussure. Génesis y evolución de su pensamiento en el marco de la linguiística occidental. Madrid, Gredos.

.(2008) "Hermann Paul and general linguistic theory". Language Sciences 30: 102-132.

LEHMANN, W. P. (1967) A Reader in Nineteenth Century Historical Indo-European Linguistics. Indiana University Press. Disponible en internet: http://ling.11l.hawaii.edu/faculty/stampe/Linguistics/ LehmannReader/00index.html (último acceso 24/08/2008).

LYONS, J. (1971) Introducción en la lingüística teórica. Barcelona, Teide [1986].

MASTRELLI, C. A. (1953) Elementi di linguistica indeuropea. Firenze, Società Editrice Universitaria.

Mc MAHON, A. (1994) Understanding language change. Cambridge, Cambridge University Press.

MELMAN, C. (1992) Imigrantes. Incidências subjetivas das mudanças de língua e país. São Paulo, Escuta.

MILNER, J.-C. (1980) El Amor por la lengua. México, Nueva Imagen.

.(1989) Introducción a una ciencia del lenguaje. Buenos Aires, Manantial [2000].

.(2002) El periplo estructural. Figuras y paradigma. Buenos Aires, Amorrortu [2003].

MOUNIN, G. (1967) Historia de la lingüística. Desde los orígenes al siglo XX. Madrid, Gredos.

PAUL, H. (1909) Extraits des Principes de l'Histoire des Langues [Prinzipien der Sprachgeschichte, Halle: Max Niemeyer, 4e éd. 1909], trad. Alexis Michaud, [1998] ms. disponible en internet: http:/ /ed268.univ-paris3.fr/lpp/pages/EQUIPE/michaud/ressources/

ROBINS, R. H. (1984) Breve historia de la lingüística. Madrid, Paraninfo.

SILVEIRA, E. (2007) As marcas do movimento de Saussure na fundação da lingüística. Campinas, Mercado de Letras.

TAGLIAVINI, C. (1963) Storia della linguistica. (Estratto da: Introduzione alla Glottologia, V Edizione: Volume I, 19-380) Bologna, Pàtron. 